\title{
Profiling illegal waste activity: using crime scripts as a data collection and analytical strategy
}

\begin{abstract}
The illegal treatment and trade of waste is an international problem which is widely assumed to be both evolving and growing. Emergent forms of criminality such as this often have the problem of data being in scarce supply, and as a result are difficult to study, and subsequently understand. In this paper we introduce the methodological concept of script analysis to assist a more objective assessment and understanding of illegal waste activity. This includes using crime scripts in two ways; to help identify data requirements, and as a tool to analyse illegal waste processes. We illustrate the utility of this methodology using waste electrical and electronic equipment. In doing so, we argue that this approach elicits a specific, focused account of what illegal activity has occurred, and nests it within the wider context of the waste management system. We anticipate that using this methodology will provide academics and practitioners a means of enhancing the investigation, detection and prevention of illegal waste activity.
\end{abstract}

\section{Keywords:}

Crime analysis; script analysis; waste electrical and electronic equipment (WEEE); crime prevention; green criminology.

\section{Introduction}

The topic of waste has been a cause for concern for environmentalists for at least 40 years ${ }^{1}$. In the 1970 s this was primarily a waste management issue related to population growth, but in recent years criminogenic features have increasingly emerged. These have included the illegal dumping of waste, the illegal trading of waste, and the opportunities in the illegal transfer of waste to facilitate these two primary processes. The magnitude and nature of illegal waste activity is, however, not clearly understood. This is due to the difficulties associated with identifying what the issues are; exacerbated by the clandestine character of illegal waste activity, and poor standards in the recording of it by public agencies. The current situation is also compounded by a regulatory-driven approach that places more focus on enforcing compliance to environmental regulations than understanding the nature of illegal waste activity and how it is best inhibited.

In this paper we introduce the methodological concept of script analysis to assist a more objective assessment and understanding of illegal waste activity. This includes using crime scripts in two ways; to help identify data requirements, and as a tool to analyse illegal waste processes. We begin by defining 'illegal waste activity' and discuss where this form of criminality sits within the criminological imagination. We then describe the legislative and political background that provides the context against which these issues have emerged. Next, the key issues regarding the data recording and data quality of illegal waste activity are identified. Lastly, the script analysis process is outlined, and an example of waste electrical and electronic equipment offered to crystallise the approach and to demonstrate its utility.

\section{Criminology and illegal waste activity}

The term 'illegal waste activity' is used to mean any movement of waste which is not in accordance with environmental regulations. This encompasses a wide spectrum of activity, with both domestic and transnational dimensions. At the gravest end of the scale it refers to the illegal trading of hazardous waste and the sequential illegal dumping of it, often in developing nations. At the other end, it includes minor incidents involving the improper storage, transfer or disposal of waste that can support more serious offences.

\footnotetext{
${ }^{1}$ See details about the inaugural edition of the UK publication 'The Ecologist' from July 1970 http://www.independent.co.uk/environment/the-ecologist-four-decades-of-global-warning-2036135.html
} 
To date, research on illegal waste activity has covered a wide gamut of themes and spanned many disciplines. Studies into regulatory systems, the international trade network, and white-collar crime issues have all contributed to this research agenda. There has also been a considered debate on where illegal waste should be situated within the criminology discipline.

Some have felt that the term 'environmental criminology' would be a suitable title to describe this field of study, but this was claimed by another sub-discipline of criminology concerned with the criminal event and its immediate circumstances (Brantingham and Brantingham, 1981). Although environmental criminology has been used to study a wide range of crime types it does not specifically focus on issues pertaining to environmental harm. There are however certain principles of environmental criminology that may usefully apply to the study of illegal waste activity. We expand on this in a later section.

A term that has become commonly used is 'green criminology' (Lynch, 1990), however, there has been much deliberation about this label due to its presumed political connotations (White, 2008). Other scholars have proposed that the term 'conservation criminology' be adopted (Herbig and Joubert, 2006; Gibbs, Gore, McGarrell and Rivers, 2010). Here, the emphasis is on crimes which impinge on the conservation of natural resources.

For the purposes of this paper, we adopt the 'green criminology' term to refer to the field of criminological study that is predominantly interested in illegal waste activity. We consider this term to be most suitable because it asserts that the "central aim of green criminology is to investigate the nature of environmental harm" (White, 2008: 27). This specifically calls for the exploration of proactive measures which can be used to monitor and prevent environmental harm, and the investigation of the causes or conditions of environmental crimes.

\section{The political and legislative context}

Since the late twentieth century many countries have seen a political shift towards environmentallysympathetic policies. Assisting this development has been the international scandals regarding hazardous waste trafficking that began in the 1980s, and continue to this day ${ }^{2}$. International condemnation of such scandals led to the creation of the Basel Convention - the primary role of which was to devise an international treaty to govern the transnational movement of hazardous waste. This voluntary treaty came into force in 1992, and to date has 173 countries signed up to it.

Against the backdrop of the Basel Convention, the European Commission (EC) launched a series of Directives from the late-1990s, which purposely defined the conditions of handling and disposing of waste. These Directives require EU member states to 'transpose' this legislation into their national framework within a timeframe, without dictating how that ought to be achieved. The 'Landfill Directive' (1999), was one of the first of these. Along with some technical requirements, this prescribed the classification of landfills into hazardous, non-hazardous or inert sites. The Directive also set out 'waste acceptance criteria' which determined the standards that waste had to meet to be accepted at each class of landfill. Furthermore, it outlined targets for the reduction of biodegradable waste reaching landfill, and prohibited priority hazardous waste such as tyres and highly flammable, explosive or corrosive liquid. Several other Directives were subsequently created, covering specific waste types such as batteries, end-of-life vehicles, and waste electrical and electronic equipment (known as WEEE). Collectively, these Directives aim to reduce the amount of waste created in the first place, and to encourage the reuse, recycling and recovery of materials wherever possible. Implementation of these Directives into domestic legislation has varied considerably across member states ${ }^{3}$. In the UK context, they were transposed into law through environmental regulations.

\footnotetext{
${ }^{2}$ For a high profile example of this readers are referred to the following website: http://www.independent.co.uk/news/world/europe/trafigura-fined-over-toxic-waste-2033813.html

${ }^{3}$ See for example http://europa.eu/legislation summaries/environment/waste management//21208 en.htm
} 


\section{The increase in criminogenic opportunity and activity relating to waste}

The introduction of legislation which imposes stricter regulatory controls on the handling and disposal of waste has in turn made the management of waste a more complicated and expensive activity. This has had five principle consequences on the increase of illegal waste activity:

- The creation of new 'crimes' e.g. the landfilling of certain waste types is now illegal.

- The criminalisation of activity that had previously been legal e.g. the movement of certain waste between one location and another requires the transporter to have a licence to permit the activity. If they are not an authorised carrier, then the transportation of waste is an illegal activity.

- Waste, by its very nature, is easily manipulated. Different categories of waste can be mixed together which can facilitate deception - it can mask the real activity. Manipulating the management of waste in this way includes exploiting the second hand goods market to serve as a cover for illegal waste exports - second hand goods are permissible for export, whereas waste is not. The distinction between what is second hand and what is waste has been contentious, and can provide an opportunity for criminal exploitation.

- The tightened regulation of waste disposal methods has resulted in waste being referred to as a 'commodity', which itself leads to new market conditions in how it is managed (White, 2008). This can result in a much wider geographic spread of activities relating to waste because its creation, storage, treatment and disposal can occur anywhere. The disassociation between the people producing waste and those who are disposing it can cause problems of accountability failure.

- Criminal opportunity stemming from market conditions; the requirement to manage waste appropriately (following legal conditions) has resulted in new waste markets being developed, and when any new market develops criminal organisations may seek to explore the potential to illegally profit from those markets (Schmidt 2004). The waste management industry is also complex, made up of many different operators (often sub-contracting tasks), large and small. This complexity results in a porous system, providing the potential for waste to easily escape the legitimate environmental conditions which should govern it, and for corners to be cut. That is, the 'pathological pursuit of profit' (Baken, 2004), can be seen as the motivating factor for carrying out illegal waste activity (which is not sufficiently tempered by the perceived risk of being caught).

One of the most serious consequences of the globalisation of waste disposal is that it has intensified the impact of corporate, or 'white-collar' crime (Gibbs, McGarrell and Axelrod, 2010), and made the whole industry a great deal harder to monitor and police. Whilst legislation and the EC Directives have encouraged a greater transfer of enforcement powers to regulatory agencies and an increase in enforcement activity, this has been at a pace that has not matched the growth and the scale of the waste management market. The sheer number of people involved in the industry makes it a continual challenge to detect illegal transactions (Elliot, 2009). This can then have the knock on effect of undermining enforcement activity if it is difficult to identify who to direct it to.

The actual scale and magnitude of illegal waste activity is not well known. Illegal waste activity is often reported to be widespread (e.g. Simon, 2000; Block, 2002), and the money making potential is purported to be high (one assessment put the annual worldwide criminal revenues at US\$12 billion (Schmidt, 2004)). Illegal disposal is estimated to provide an economic saving of between $200-400 \%$ the cost of legitimate disposal (Bruinsma, 1996; Massari and Mozzini, 2004).

Although few systematic studies of illegal waste activity have been conducted, what is thought to be clear is that illegal waste activity is a growing problem, across Europe and on the wider international stage. Whether this is because it is becoming more visible in the public and political consciousness is 
debatable, as there are no volumetric measures available for long term trend analysis. However, the general criminal opportunity and potential for illegal financial gain that is present in the waste management market is clear.

The considerable efforts of non-government organisations (NGOs) have revealed that illegal waste activity is undertaken on a large enough scale to cause serious damage to both the environment and humans exposed to it. Recognition has also been growing amongst governments of the risks and harms associated with this criminal activity. Notably, the United Nations Environment Programme (UNEP) has raised the profile of the burgeoning 'waste crisis' (so called by White, 2008) through holding international conferences and commissioning research. A recent study by UNEP highlights that unless significant investment in waste infrastructure is made in developing nations who are the current recipients of hazardous waste, the problem of illegal waste disposal is only set to grow (UNEP, 2010). At a European level, a threat assessment completed for Implementation and Enforcement of Environmental Law (IMPEL) concluded that a 'significant level' of illegal exports originated from EU member countries, and that sometimes the importing countries were EU member countries with low enforcement capacity (Czarnomski, Webb and Holmes, 2006).

In recognition of the serious and growing problem of illegal waste activity (alongside other crimes relating to the environment) and the need for a globally coordinated law enforcement response, in 2009 Interpol established the Environmental Crime Programme. This is a group of externally funded Interpol staff who are dedicated to mobilising the environmental enforcement community and serves to highlight the increasing importance that law enforcement is assigning illegal waste activity.

\section{Data recording and quality}

Data issues on illegal waste activity are internationally recognised to be a problem. The IMPEL threat assessment referred to previously highlighted a lack of data on the 'scale and breadth' of illegal waste activity, and that EU member states do not have the means available to estimate the volume of legal waste movements, let alone the illegal percentage. This is largely to do with the fact that most movements (i.e. exporting and importing) are not subject to any pre-notification requirements, which means that the authorities are not consistently informed about this type of activity. However, illegal waste activity is a relatively new legal concept and subject of study (Gibbs and Simpson, 2009), so perhaps it is natural that it takes time for appropriate recording systems to emerge. For example, it has only been in the last 20 years that police agencies have systematically managed the recording of incidents of crime electronically, even though in some cases these agencies have existed for centuries (Ratcliffe, 2008).

The sheer number of agencies and operators involved in governing and processing waste is an important factor that inhibits the recording of good quality data. The governance of waste management has traditionally involved law enforcement and customs agencies dealing with the transport of waste, whilst administrative controls - such as licensing and site inspection - are usually carried out by national regulatory bodies (Dorn, Van Daele and Vander Beken, 2007). This therefore stresses the need to ensure that any data that are recorded are shared between these agencies in order to cross-reference intelligence and other information on (suspected) illegal activity. In practice, the sharing of information is problematic, as identified in other fields of criminal intelligence gathering (Home Office, 2010), and can undermine a proper and more complete assessment of criminal activity.

There are also several thousands of operators and sub-contractors working within the waste management industry - at least in the UK - of various sizes (i.e. from large corporations to small, family-run businesses). Each of these is competing for their own share of the market, whether it is in waste collection, storage, processing or the disposal of waste. It requires strict adherence to data recording practices across the private waste management sector if illegal activity is to be suspected and identified (at least by those operators who on the surface appear to be acting legitimately). However, as these are not routinely monitored it results in the administration of waste management 
often not being complete, or recorded in a manner that supports the systematic analysis of criminal activity.

Data collection on waste management is arguably a regulatory-driven endeavour. By this we mean that few incidents of illegal waste activity are likely to be reported to the police, customs or regulatory agencies by the public, and any operator acting illegally would serve their own interests by keeping their activity as secret as possible. Environmental crimes are predominantly derived from regulatory activity such as inspections or investigations. In this way it is analogous to other forms of mainstream crime such as drug dealing, that are primarily discovered through police activity. This means that a significant amount of illegal activity is likely to be unidentified and unrecorded, and what is recorded can be more a measure of regulatory activity, rather than a true measure of illegal activity. Even the data that are recorded at site inspections and licensing requests can be difficult to use as Gibbs and Simpson note - "environmental violation data [is] complex, difficult to use, and not easily amenable to corporate or hierarchical research" (2009: 88). For example, US Environmental Protection Agency (EPA) data are recorded at the facility level (e.g. mill, refinery, etc.), making it difficult to analyse the flow of waste from one destination to another in order to identify suspected illegal activity.

Together, these data issues hamper the collective ability to conduct research on the nature of illegal waste activity. Data are the bedrock of any approach that supports the generation of evidencebased decision-making. At present, the ability to conduct research that seeks to understand illegal waste activity is hampered by data recording deficiencies.

\section{A new methodology for understanding illegal waste activity}

This paper proposes a methodology that can help to improve the assessment and understanding of illegal waste activity. We do this by adapting and applying a technique that has been developed in research emanating from environmental criminology; a technique known as crime scripts. Through identifying key questions that need to be answered in order to build a profile - or script - of illegal waste activity, we demonstrate how this methodology can be used to direct a data collection strategy and an objective analytical approach. We argue that this approach elicits greater clarity on the many entangled legal and illegal processes, and activities of interconnected participants (both organisations and individuals) involved in the management of waste. We illustrate this methodology by developing a crime script for a specific waste stream - WEEE.

Through the use of this script example, we illustrate how social, structural and economic conditions give rise to the motivation to engage in illegal waste activity - which contributes to a 'working typology' of environmental crime (White, 2008). The example also illustrates how the crime scripts methodology can help to identify specific points of vulnerability in waste management (i.e. where waste may depart the legitimate system and is directed towards illegal paths), and identify the best opportunities for the detection of criminal activities. We anticipate that using this methodology will provide academics and practitioners a means of enhancing the investigation, detection and prevention of illegal waste activity.

\section{Script analysis as a methodological tool for understanding criminal activity and behaviour}

The movement of waste from the creation stage to the disposal stage can be a complicated process, involving many different participants. We propose that it therefore makes sense to consider the application of a methodology that can help to systematise the features of this complex flow, by breaking each procedure and activity of waste management into clearly articulated components.

Script analysis has long been used in cognitive science to clarify issues relating to the production and understanding of an action of sequences. Its purpose is to organise knowledge that pertains to understanding and enacting commonplace behavioural processes or routines. In constructing a script, it is necessary to understand the event sequences of a particular behaviour, and that these 
have inherent causality. In other words, those events occurring early in the sequence produce or enable the occurrence of later events (Nisbett and Ross, 1980).

In the first instance, consider this example of a sequence of events relating to a particular activity that involves going to a restaurant for a meal. This restaurant meal 'script' consists of the following: enter; wait to be seated; be shown to your table; receive the menu; decide on your choices; order; be served; eat; ask for the bill; pay the bill; and exit. This illustrates how each event can be broken down, how they operate as a sequence, and how events that occur upstream relate to those that occur downstream, and vice versa.

The concept of script analysis draws from its natural analogy with the theatrical world. Scripts have actors associated with them, require props (such as tools or equipment) and take place in a variety of specified locations. A theatrical script deals with the mechanics of breaking down plots into acts and scenes so that there is some organisational structure to the storytelling, which in turn helps the overall plot to be more readily understandable.

In recent decades, criminologists concerned with opportunity-reduction have recognised the value in applying these scripting principles to the examination of crime commission (Brantingham and Brantingham, 1984). In his seminal paper, Cornish (1994: 175) describes scripts as "...simply a way of highlighting the procedural aspects of crimes. In doing so, they emphasize the form of crime as a dynamic, sequential, contingent, improvised activity, and the content of specific crimes, considered as activities with particular requirements in terms of actions, casts, props and spatio-temporal locations".

Such an approach was originally borne out of, and seen as a logical extension of, rational choice theory (Cornish and Clarke, 1986; Cornish, 1994). In environmental criminology (referred to in section 2), the rational choice perspective is commonly adopted as a decision-making framework of criminal offending. This contends that criminal behaviour is purposive and deliberate insofar that it serves an offender's perceived needs or desires. In essence, the crime benefits the offender in some way (and not necessarily limited to economic benefits). Related to this is the assumption that all human action is considered rational to some degree; we all have choices and we all have free will. These choices are structured by the characteristics of the situation, despite the fact that humans operate under conditions of imperfect information. Hence, behaviour is considered to be situationally determined under this perspective. Therefore criminal actions are tantamount to noncriminal actions; a person will weigh up the pros and cons, or costs (the risk of being caught) and benefits (the reward of getting away with it), before making a choice. Acknowledging this rationality means that it is possible to view a situation dispassionately from an offender's viewpoint; hence uncovering influencing factors that may cause a particular choice to occur.

Rational choice perspective has been eagerly embraced by many researchers studying (presumed) economically motivated criminal behaviour, such as white-collar crime (Paternoster and Simpson, 1993). However, critics have objected that it does not explain seemingly irrational behaviour - such as the offender being intoxicated, or exercising an apparent lack of foresight when committing a crime. Furthermore, some scholars have questioned whether habitual decision-making actually entails making a choice or whether behaviour is somewhat governed by routinized internal processes (Wikström, 2006; Kennedy, 2008) which involve little, if any, deliberation. In response to this Cornish and Clarke (2008) emphasise that the rational choice perspective does not set out to explain all criminal behaviour. Instead, it focuses on being a clear and parsimonious framework through which to assess criminal decision-making, with an explicit focus on preventing, disrupting and detecting criminal actions. We take the position that rational choice perspective provides a useful decision-making framework to couch script analysis within. That said, we acknowledge that other, more sophisticated, frameworks exist and these may prove to be an attractive alternative to use for the purpose of creating scripts. As long as a decision-making framework facilitates the social, 
legal and situational variables influencing action to be identified, it is unimportant which framework is used to create crime scripts.

Crime scripts describe the ways in which an offence unfolds and make explicit the series of decision points through which the would-be offender passes in the process of crime commission. Hence, scripts are essentially a distillation and systemisation of practical wisdom about the modi operandi. In order to construct a script, one needs to consider or gather information on how the offender went about the crime commission, and the rational (or otherwise) choices that were made by the offender. This can include how they accessed the crime scene, the skills they required, the effort involved, information about the crime opportunity, the financing required to carry out the crime, facilitators (tools, transport, weapons, communication), and technical expertise. Such information is rarely available in standard crime reports made by law enforcement agencies or regulatory bodies, and requires a dedicated effort on the part of the researcher to source. The formation of a crime script can draw from multiple information sources; interviews with offenders (to get their crucial viewpoint), detailed investigative notes, or else, can be inferred by those intimate with the details of the criminal event.

Since the concept was introduced in 1994, script analysis has been applied in a variety of ways to study a range of crime types. Tremblay, Talon and Hurley (2001) used it in a pioneering research paper to provide a case study of the 'sustained crime expansion' in vehicle ringing (the forged identity of a stolen vehicle). Lacoste and Tremblay (2003) later used this approach to systematically analyse cheque fraud in Montreal. More recently, rape scripts have been derived using multiple correspondence analysis and hierarchical cluster analysis to analyse the hunting behaviour of serial sex offenders (Beauregard, Proulx, Rossmo, LeClerc and Allaire, 2007). Script analysis has also been merged with social network analysis by Morselli and Roy (2008) in order to understand the significance of 'brokers' within stolen vehicle exportation (ringing) operations.

Script analysis is also gaining recognition as a conceptual tool to better understand likely scenarios that lead to the commission of crime. When considering the requisite resources needed by offenders to commit crime, Ekblom and Tilley (2000) endorse the script analysis approach for highlighting what options for displacement (change of tactics, target or timing) are realistically available to the offender. In another study, Ekblom and Sidebottom (2008) consider its application in the design of products, to make them less attractive to criminals by considering the interplay between a product owner's script and the potential offender's script, so that the probability of theft is reduced. Likewise, Willison and Siponen (2009) advocate the application of script analysis in studying employee computer crime within the emergent cyber-crime field.

\section{Adapting script analysis for illegal waste activity}

To date, script analysis has mainly been used as a methodological tool by criminologists working on behalf of policing agencies to better understand the process of crime commission. The method as it was originally proposed requires a detailed consideration of the decision-making process an offender may go through. For the purposes of greater practical utility, and its application to illegal waste activity, we felt that many of the processes involved in script analysis needed to be streamlined, but without undermining the conceptual principles of the methodology.

To start with, we believed it was important to use language that was more universally understood, rather than the terminology used in cognitive psychology where the technique originated. We further thought that the structure of the scripts used to analyse illegal waste activity would benefit from being simplified.

We began by deciding upon the term 'act' as the label for each of the main process stages involved in the management of waste. The original crime script methodology refers to these key stages as 'scenes', a term which we decided was best reserved in our adaption to describe another process. Determining these key stages (acts) drew on previous research into illegal waste activity, by using 
the six categories defined by Czarnomski et. al. (2006): creation, storage, collection, transport, treatment and disposal.

The original script analysis methodology refers to 'facets' to explain the ways in which a key stage (act) could be executed. We felt this term would mean little to practitioners involved in environmental crime law enforcement, who we hope will be the primary recipients of the results of this methodology. So instead we settled on the term 'scene', as it was easier to consider this as a process nested within an 'act' i.e. describing the 'scene' in relation to the treatment of waste.

Next, we condensed the original eleven 'scene classifications' into four. The rationale behind this was that in comparison to other types of crime, information on illegal waste activity is still scarce. We selected the requirements for these four classifications with care to ensure that they captured the relevant points for articulating a specific script. Additionally, the adoption of four classifications would make our adaptation of script analysis simple enough to understand, without compromising the detail needed to understand the script.

Our next refinement was to alter the 'choice-structuring' conditions which give rise to offenders' decision-making (originally espoused in Cornish, 1994) and adapt them so that they were readily coherent to those working within environmental law enforcement. Mindful of the multiple agencies that are involved in monitoring illegal waste activity, we stratified these into 'offending' conditions (i.e. why did the offender behave in this manner) and 'enforcement' conditions (i.e. to help identify who was responsible for monitoring compliance at a particular point in the script). This assists in making it clear where practitioners from different agencies fit within the waste flow process.

\section{Proposed script analysis process}

The script analysis process involves constructing a description of a number of events into a structured sequence, which together, can help to develop an understanding of the illegal waste activity. To do this, it requires an attempt at answering questions relating to the skills that were required, the resources that were needed, and the effort involved in carrying out the activity. That is, it involves thinking as the offender may have done - a process known as 'thinking thief' (Wortley and Mazerolle, 2008). This involves a combination of expert knowledge, interview with offenders, crime scene analyses of modus operandi and a degree of inference from those intimate with the case.

There are four steps involved in applying the script analysis process for illegal waste activity.

\section{Step 1 - Breaking the script down into 'Acts'}

Acts are the key stages involved in a waste flow process. There are six acts: the creation, storage, collection, transport, treatment and disposal of waste. Waste management of all types involve these acts, although the ordering and emphasis may differ for each, and in some cases acts may be combined. For example, for some types of waste - such as municipal waste from householders - the collection and transport stages can be a combined activity and may therefore be considered as a single act. Organising the script in this way offers the first important step of breaking it into smaller, more manageable, pieces of what can be considered at times to be a complex problem. It provides a useful means of helping to structure the thinking and investigative process into illegal waste activity.

\section{Step 2 - Writing the script - describing the scene, the cast and the activities}

Writing the script provides the means of organising what is currently known about the illegal activity, alongside other information about the potential opportunities for illegal waste activity. This is structured by populating this information under each of the acts. This process also identifies where there are key information gaps and the types of extra information that would be useful to collect, such as particular facts or evidence that may be required to support an investigation into suspected criminal activity. For example, information may exist about an operator (suspected of illegal waste activity) who collects demolition waste from a construction site, but it is not known where this 
operator then disposes of the waste. In order to better understand the suspected illegal activities of the operator it would be beneficial to seek out information about where the waste is being transported to for treatment, or where demolition waste has recently been illegally disposed.

Writing the script involves describing the scenes, cast and activities that make up each act. This is illustrated in Table 1. It also involves describing several 'prerequisites' and 'facilitators' to help understand the conditions that may lead to why offending occurs.

\begin{tabular}{llllll} 
CREATION & STORAGE & COLLECTION & TRANSPORT & TREATMENT & DISPOSAL \\
\hline Scene: & Scene: & Scene: & Scene: & Scene: & Scene: \\
Cast: & Cast: & Cast: & Cast: & Cast: & Cast: \\
Activities: & Activities: & Activities: & Activities: & Activities: & Activities: \\
\hline
\end{tabular}

Table 1 - A template for organising information for each 'act', by populating the table with information relating to the 'scenes', 'cast' and 'activities'.

Scenes: A scene is the setting within which the act takes place. Information relating to the scene is organised into four scene classifications:

I. Preparation - this requires the practitioner to consider what opportunities exist for committing illegal waste activity (i.e. by 'thinking thief'). This can help to identify the opportunity structure for illegal waste activity.

II. Pre-activity - this relates to the logistical or transactional steps that need to be carried out prior to the activity.

III. Activity - this relates to the illegal waste activity itself, and can take the form of various offences or non-compliance.

IV. Post-activity - this refers to logistical or transactional steps necessary to exit from the illegal activity.

Cast: Within each scene there will be a number of participants, or actors. The cast describes these individuals and organisations. The leading actor is the key offender (or group of offenders if applicable). Supporting cast members are the individuals, businesses and agencies whom the offender is interacting with, and may include actors who are behaving legitimately.

Activities: This stage involves describing the activities that have taken place under each act (or can potentially take place).

Table 2 provides an example of the types of information that can be used to populate an act, structured in relation to the scene classification, cast and the corresponding activities. This example is based on an illegal waste tyre operator ${ }^{4}$ and shows the utility of script analysis for helping to reveal the relationship between what is known about the illegal activity and the potential opportunity structure that helps to facilitate the activities.

\footnotetext{
${ }^{4}$ See http://www.environment-agency.gov.uk/news/126796.aspx for details of one such scenario.
} 
Tyres being COLLECTED by an offender

\begin{tabular}{|c|c|c|}
\hline $\begin{array}{l}\text { Scene } \\
\text { classification }\end{array}$ & Cast & Corresponding activities \\
\hline Preparation & $\begin{array}{l}\text { Offender - rogue waste } \\
\text { tyre collector: } \mathrm{Mr} \mathrm{A} \\
\text { (leading actor) }\end{array}$ & $\begin{array}{l}\text { Offender is aware that independent garages need to maximise } \\
\text { profits and identifies an opportunity to undercut legitimate } \\
\text { tyre collectors. }\end{array}$ \\
\hline Pre-activity & $\begin{array}{l}\text { Offender: Mr A (leading } \\
\text { actor) } \\
\text { Independent garage } \\
\text { owner: Mr B, Shireville } \\
\text { Garage (supporting cast } \\
\text { member) }\end{array}$ & $\begin{array}{l}\text { Offender approaches owner of independent garage (useful } \\
\text { data to collect/record by practitioner: address, date, time of } \\
\text { day, size of garage) and explains he can reduce their current } \\
\text { tyre removal costs. He produces fraudulent paperwork that } \\
\text { purports him to have an appropriate environmental license. } \\
\text { The owner of the independent garage agrees to the } \\
\text { transaction. }\end{array}$ \\
\hline Activity & $\begin{array}{l}\text { Offender: Mr A (leading } \\
\text { actor) }\end{array}$ & The tyres are loaded into the offender's vehicle. \\
\hline Post-activity & $\begin{array}{l}\text { Offender: Mr A (leading } \\
\text { actor) }\end{array}$ & $\begin{array}{l}\text { The offender takes with him the fraudulent environmental } \\
\text { license so that the garage owner cannot verify its legitimacy. }\end{array}$ \\
\hline
\end{tabular}

Table 2 - Scene classifications and their corresponding activities. Names are entirely fictional, and are only included for illustration.

Prerequisites and facilitators help to describe the 'offending conditions' for each scene classification, which the leading actor (i.e. the offender) may have taken into consideration to inform their decision making. The type of scene classification determines what conditions are relevant.

Prerequisites: these represent the likely preconditions that need to be satisfied before illegal activity is initiated. The prerequisite condition involves attempting to answer questions that help to identify the props (or tools) that the offender will have used to commit the illegal waste activity; these may be cognitive or physical tools. Without these tools, illegal activity is not possible. They are therefore most relevant for those scene classifications that support the illegal waste activity; the preparation, pre-activity and post-activity.

Facilitators: these define the factors that make it easy and profitable for the offender to engage in the illegal activity. The facilitator condition involves attempting to answer questions that help to identify the enabling features that are acting as a catalyst for the illegal waste activity. For instance, if the offender perceives the rewards of their activity as lucrative, and the risks of being caught as low, then this increases the likelihood of the illegal activity taking place. The facilitator condition questions are thus most relevant to the 'activity' scene classification, and capture the motivations and drivers that underpin the illegal waste activity.

Table 3 lists the types of questions that can be asked to help establish the influence of the prerequisite and facilitator conditions. The key benefit in gathering information on each of these conditions is that they can help to identify potential prevention and detection strategies. For example, if an offender perceives the risk of being caught as moderate, and the costs of being caught as low (e.g. any fines are a relatively small amount to pay in relation to the profits that are made from the criminal endeavour), then increasing these costs may act as a stronger deterrent to help reduce, or at best prevent, future illegal activity, rather than increasing enforcement to catch more offenders.

For each scene classification, it is also useful to identify which legislation, licence or regulations govern the illegal waste activity, and which agency is responsible, or best placed to enforce these controls (see Table 3 for examples of the types of questions to attempt to answer). These are termed as 'enforcement conditions'. 
Responsibility: First, the agency that has overall responsibility for addressing the illegal activity should be identified. This helps multiple agencies identify the particular activities that come under their purview, and if there are any overlapping responsibilities across different organisations. The agency that is seen to have the main responsibility for enforcing against the illegal activity then needs to identify the powers that are available to them to help address this illegal activity (e.g. a warning letter, a prosecution etc.).

Legislation and regulations: a useful final stage is to describe the legislation, licensing terms and regulations that govern the act. Since these can only apply to the illegal activity itself, they are most relevant to the 'activity' scene classification.

\begin{tabular}{|c|c|c|}
\hline Condition & & Relevant questions to consider \\
\hline \multirow[t]{8}{*}{ Offending conditions } & \multirow[t]{4}{*}{ Prerequisites } & What physical equipment is required? \\
\hline & & What human resources are required? \\
\hline & & What knowledge is required? \\
\hline & & Is there an awareness of the rewards of legitimate choices? \\
\hline & \multirow[t]{4}{*}{ Facilitators } & Is this a reciprocal interaction between cast members? \\
\hline & & What rewards are on offer? \\
\hline & & What is the perceived risk of being caught? \\
\hline & & What are the perceived costs of being caught? \\
\hline \multirow[t]{4}{*}{ Enforcement conditions } & \multirow[t]{2}{*}{ Responsibility } & $\begin{array}{l}\text { What agency has responsibility for the enforcement of this } \\
\text { activity? }\end{array}$ \\
\hline & & What powers are available to enforce this activity? \\
\hline & \multirow{2}{*}{$\begin{array}{l}\text { Legislation and } \\
\text { regulations }\end{array}$} & What legislation governs this activity? \\
\hline & & What permit conditions are related to this activity? \\
\hline
\end{tabular}

Table 3. Relevant questions (to attempt to answer) to help populate the script with an understanding of offending and enforcement conditions.

The first two steps in the script analysis process therefore help to determine a strategy for identifying, collating and organising information that is available about the illegal waste activity under investigation. It also provides an opportunity to consider the conditions that may give rise to the illegal activity. Several information gaps will likely remain (e.g. information from one agency was not available, or the information just did not exist), but it will have helped to structure the information in a meaningful way, and importantly introduced a vital level of specificity to the analysis of the illegal waste problem. Problems are best understood when they are clearly defined, and there is a level of detail that helps to offer some exactness to its occurrence i.e. interpreting why the problem has occurred from the information that is collected. This approach also then begins to make it easier to identify the causality within the process, and assists in illustrating that certain types of illegal activity can be prevented or reduced by closing down an earlier, precursory stage. The inclusion of the responsible agency and relevant legislation against each act can be used to identify who is best placed to tackle the issue, and what powers exist to help this process.

\section{Step 3 - Interpreting the content of the script and visualising the results}

Now that the information on the illegal waste activity has been collated, the next stage involves attempting to make sense of it all - conducting an analysis of the information from each act and interpreting what it means. 
The point the user should try to reach is one where they can confidently explain the illegal waste activity. This is commonly achieved by working through the process of Who, What, Where, When, Why and How the illegal waste activity has come to exist (Boba, 2005). They may not have all the evidence they require to pursue a prosecution, but their analysis should help them to identify how they can prevent future problems and the intelligence gaps that relate to the current criminal investigation.

Once the content of each act has been analysed, the next stage involves interpreting these results as an overarching script. It is helpful to think of the 'script' as a story, that has a beginning and end. This helps to connect the many pieces of information together. A flow chart is a useful tool to help interpret the results of the analysis, and to illustrate the script as a waste flow process. The flow chart can describe the 'cradle to grave' activities that occur in relation to a waste stream and is most intuitive when overlaid onto the six 'acts' (or variations thereof when conditions require the acts to be combined). Legitimate pathways for waste to flow can also be added, to explain the wider context in which the illegal activity is occurring.

In line with Cornish's original recommendation, we suggest that a sensible strategy for creating a 'masterscript' might be to start with a single, known, crime event. Once this has been subjected to script analysis, the terrain of this type of offending is roughly sketched out. From here, further crime events can be compared against this original script to see whether there are any similarities. If they share several features, it may be worth creating a different 'track' within the script. Tracks are defined as different permutations of a script family; thus a masterscript will subsume several specific tracks. For instance, if we recall the restaurant script introduced in section 7 , we can elaborate on this general script so that it relates to going to a fast food restaurant; this would be a specific track. Another track might be a script of going to a sushi restaurant, where there is a different system of ordering food. A final track might be going to a fine-dining restaurant, where the script scenes may diverge from the others. Thus, families of related tracks can be linked together into a masterscript, which helps to build up a composite scenario. Conversely, a masterscript can be broken down into tracks should the situation call for complete specificity.

Tracks may relate to differential motivations (e.g. illegally collecting tyres for domestic storage and subsequent abandonment versus collecting tyres for illegal export), but should share some salient characteristics when classifying them together. What those characteristics might be is not welldefined in extant literature, but rely on the researcher or practitioner having a conceptual base for linking these events. Cornish (1994: 168) does though acknowledge that as criminal activities evolve, groupings of crime incidents into tracks becomes tentative and may not have enduring practical value.

\section{Step 4 - Identifying how to tackle the problem}

Good analysis, which explores the specifics of a crime problem, often makes it easier to see how the problem can be tackled. The script analysis approach outlined in this paper can add structure to the way an illegal waste problem is considered, and offers a means of drawing out the necessary detail that is required to help understand the problem. It also assists in determining which agency is well placed to respond to illegal activities that have been identified from the analysis, and can stimulate debate and establish lines of further enquiry. This has the potential to culminate in substantial support towards a prosecution if the illegal activity warrants such an enforcement path.

The script methodology also helps to draw attention to the transactions that occur between sites, rather than viewing the sites in isolation. Visualising this in the context of the legitimate system allows an appreciation of how waste can deviate from the preferred (legal) routes and the points of vulnerability in the system. Preventative strategies should therefore look to disrupt the mechanisms that are allowing a problem to occur and formulate ways of incentivising legitimate decision-making and discouraging illegitimate activity. 


\section{The practical application of the script analysis methodology}

To illustrate the utility of the script analysis approach, we offer an example of a prioritised waste stream; waste electrical and electronic equipment (WEEE). In doing so, we attempt to define some vulnerable points in the legitimate control system where it is possible for illegal waste activity to occur. For this example we describe each step of the methodology and illustrate the utility of constructing a flow chart that results from a completed script table.

This analysis was carried out using our expertise and experience into real world examples of illegal waste activity. That is, it draws from our knowledge of illegal waste activity across many incidents, rather than a particular investigation where data are too sensitive to be openly published. Where possible, we offer references to completed investigations where the information is in the public domain.

\subsection{Electronic waste case study}

Although it is well-known that electronic waste poses a grave problem in the environmental law enforcement community, it is worthy of a brief introduction for readers of this paper. Waste electrical and electronic equipment - WEEE - is widely recognised as the fastest growing waste stream in the European Union (Darby and Obara, 2005). This is due to the seemingly insatiable consumer appetite for new electronic goods. The EC WEEE Directive - introduced in January 2007 aimed to reduce the amount of these products being produced and to encourage reuse, recycling and recovery of WEEE. The UK transposed the Directive through its WEEE Regulations. This legislation promotes the separate collection of WEEE from other waste types, makes producers (i.e. the manufacturers, rebranders or importers) of electronic goods responsible for the environmental impact of their products and emphasises sound environmental disposal of WEEE. As there are many hazardous materials found in WEEE, these products are prohibited from being exported if they have reached the end of their working life under the Waste Shipments Regulations (2006). Second hand equipment however can legitimately be exported for resale or refurbishment. It is these distinctions that open up opportunities for abuse in the system and makes it challenging to detect illegitimate activity.

Producer responsibility is at the heart of the WEEE Directive. This requires each producer to be responsible for treating and recycling a volume of end of life electronic products that is proportionate to their market share. In the UK the administrative and logistical requirements of this are primarily managed by 'producer compliance schemes'. These schemes arrange contracts between producers and designated collection facilities (DCFs) to ensure that compliance with the Directive is achieved. In 2010 there were thirty such schemes approved by the UK Environment Agency (EA), and approximately 1,000-1,100 DCFs were in operation.

Once collected, the legitimate route for WEEE is for it to go to a treatment site, or sometimes an intermediary site (such as a waste transfer station) before it reaches the treatment site. These transportation costs are borne by the producer compliance schemes. These treatment sites should be either an Authorised Treatment Facility (ATF) or an Approved Authorised Treatment Facility (AATF). Both types of facility are required to have some form of environmental permit so that they can treat (test, dismantle, recycle or refurbish) the product prior to its onward movement to a reprocessor site.

The treatment facilities compile aggregate totals of how much WEEE is recycled and reused through their sites. These figures cannot though inform us of the proportion of all WEEE this is; or in other words, what percentage is processed by these legitimate operators. A lack of data on electronic goods ownership and disposal (by geography and demography) is commonly reported across much of the European Community (Axion Recycling, 2006). This hinders analysis and research on the volumes of WEEE which are exploited for illegal gain by criminals. 
For the purposes of illustrating the application of script analysis we use an example of intelligence coming to light that a shipping container has been loaded with second-hand electronic equipment, (for export) at a site which is registered as exempt from particular waste management licensing conditions. This raises suspicion and an investigation is initiated.

Step 1 involves identifying the acts that are relevant. Firstly, it needs to be determined whether the container being loaded at the identified site contains WEEE or not. This will dictate the nature of any activity that is occurring. If the products are not waste (and described correctly as second-hand electronic goods) then the activity may be lawful. Nevertheless, if the products have been tested to assess if they are waste then it can be argued that they have received treatment and this can be referred to as the treatment act.

Having related the first piece of information to an act, further information to help explain the waste flow process can be sought on the other acts:

- Extending the process backwards, it would be useful to determine where these goods were collected from, and by whom. This is the collection act.

- Extending the process forwards from what is known, it needs to be established where the container of suspicious electronic goods is destined for, and if possible, the cast involved in the transaction (i.e. is there a waste broker involved?). This refers to the transport and disposal acts.

Four acts have been identified - collection, treatment, transport and disposal - providing an opportunity to consider how these impact upon the illegal waste activity that is under investigation.

Step 2 in the methodology requires the scenes, cast and activities that are occurring in the identified acts to be described. For this example, let us say that the exempt site that is under investigation is used by an IT equipment collection and refurbishment business. This offers a service to corporations and individuals who want to dispose of redundant computers. At this site the goods are tested to determine if they are waste or working products.

The equipment in the shipping container is found to be a mix of waste and working products. This informs us that this is illegal waste activity, as it is against the regulations to export WEEE from the UK. As the exempt site has testing facilities, this cannot simply be an oversight on the part of the business owner (let us call him Mr X).

It can be inferred that the electronic equipment has originally come from a corporation who have upgraded their IT stock, as there are many similar makes and models of computer screens in the shipping container. There is a gap in the script about the particular company who supplied $\mathrm{Mr} \mathrm{X}$ with these computers and this is hence set as an intelligence requirement for the investigators.

From the shipping manifest data, it has been found that the container was destined for an importing company address in Nigeria. This complements other intelligence which suggests that Nigeria is a popular export destination for second-hand goods ${ }^{5}$, but also suffers from a large-scale problem of illegally dumped WEEE.

From the information collated, a script is populated by describing the scenes, cast and activities that have occurred. A summary of this is provided in Table 4. In the interests of brevity we have not included the scene classifications here; or the offending and enforcement conditions, but this would be advisable in a real investigation.

\footnotetext{
${ }^{5}$ For example, see http://www.environmentagency.gov.uk/news/124867.aspx?page $=8 \&$ month $=11$ \&year $=2010$
} 


\begin{tabular}{|c|c|c|c|c|c|}
\hline CREATION & STORAGE & COLLECTION & TREATMENT & TRANSPORT & DISPOSAL \\
\hline Scene: & Scene: & $\begin{array}{l}\text { Scene: } \quad \text { Large } \\
\text { companies upgrading } \\
\text { their IT equipment }\end{array}$ & $\begin{array}{ll}\text { Scene: } & \text { Large shed } \\
\text { in } & \text { residential } \\
\text { garden } & \end{array}$ & $\begin{array}{l}\text { Scene: Shipping line } \\
\text { container }\end{array}$ & $\begin{array}{l}\text { Scene: } \\
\text { Nigeria }\end{array}$ \\
\hline Cast: & Cast: & $\begin{array}{l}\text { Cast: } \mathrm{Mr} \text { X } \\
\text { actor) and lead } \\
\text { corporation } \\
\text { (supporting cast) }\end{array}$ & Cast: $\mathrm{Mr} \mathrm{X}$ & $\begin{array}{l}\text { Cast: } \mathrm{Mr} \mathrm{X} \text { (lead } \\
\text { actor) and } \mathrm{Mr} \mathrm{Y} \\
\text { (supporting cast) }\end{array}$ & $\begin{array}{l}\text { Cast: } \\
\text { Importing } \\
\text { company }\end{array}$ \\
\hline Activities: & Activities: & $\begin{array}{l}\text { Activities: } \mathrm{Mr} \quad \mathrm{X} \\
\text { provides a collection } \\
\text { service for old IT } \\
\text { equipment }\end{array}$ & $\begin{array}{l}\text { Activities: } \mathrm{Mr} \quad \mathrm{X} \\
\text { tests electronic } \\
\text { goods to determine } \\
\text { if they are waste }\end{array}$ & $\begin{array}{l}\text { Activities: Mr X books } \\
\text { the shipping } \\
\text { container, Mr Y fills it } \\
\text { with WEEE for export }\end{array}$ & $\begin{array}{l}\text { Activities: } \\
\text { WEEE } \\
\text { abandoned } \\
\text { at } \\
\text { destination. }\end{array}$ \\
\hline
\end{tabular}

Table 4. Script table summarising information that is available or has been collected to help investigate illegal waste activity relating to WEEE.

Step 3 relates to interpreting the content of the script and visualising the results. From the script written in step 2 the story of what has happened can begin to be understood. In this example, the exporting of WEEE is a by-product of a legitimate business which refurbishes redundant IT equipment. It would appear that up until the treatment state, no deliberate illegal activity occurred. The corporations that are disposing of old IT equipment are not aware of their 'duty of care' obligations and therefore commission the services of $\mathrm{MrX}$ to pick up the electronic products.

Any IT equipment with a resale value that $\mathrm{Mr} X$ collects from businesses is prepared for the secondhand market, (which may involve refurbishment work). However, there is always a proportion of each collection which is beyond repair, or cannot be resold in the UK market. Mr X has sought out ways of reducing the costly disposal fees for WEEE in the UK, and has been informed by an acquaintance that Western Africa is eager for these products.

Although $\mathrm{Mr} \mathrm{X}$ has applied for all the necessary permits and licenses, he is not fully aware of his environmental responsibilities and does not realise it is illegal to export WEEE. He stores the WEEE alongside the working redundant electronic equipment at his business premises until there is enough to fill a shipping container. Mr X liaises with a shipping agent - Mr Y - who acts as a broker between him and a willing importer for the WEEE. MrY then makes arrangements for the container to be loaded and sent to Nigeria via an importing company.

This script process has been translated into a waste flow chart and can be seen in Figure 1. Here, the acts have been realigned to the scenario, as if the products are tested to determine whether they are waste or not, then it can be argued that they have received treatment. So the treatment act comes before the transport stage in this scenario. This illustrates that the script analysis methodology can be flexible to the needs of the scenario - if it is not immediately applicable to a situation, thought can be given to how it can be adjusted to suit the circumstances of the activity under investigation.

The legitimate waste flow routes can also be overlaid onto the chart to assist thinking about how to prevent this illegal waste activity from occurring in the future. When considering the decision making that goes on within a waste flow process, other opportunities for waste to escape from the legal control system can be identified. These flow paths have been inserted onto the flow chart on top of the original information.

Step 4 involves identifying appropriate responses to the problem that has been analysed. As previously mentioned, this can be in the form of supporting a prosecution, or providing impetus into preventative strategies that seek to reduce similar criminality. The latter approach will require the 
consideration of available options that will have the greatest impact on dissuading illegal decisionmaking.

For this example, it appears that a lack of knowledge has facilitated the opportunity for this illegal activity to have taken place. Businesses upgrading their electronic equipment need to be educated as to their 'duty of care' responsibilities. Likewise, potential waste-producing businesses (such as refurbishment companies) which apply for exempt status from the authorities should have their attention drawn more explicitly to the details of the environmental regulations. This requires the 


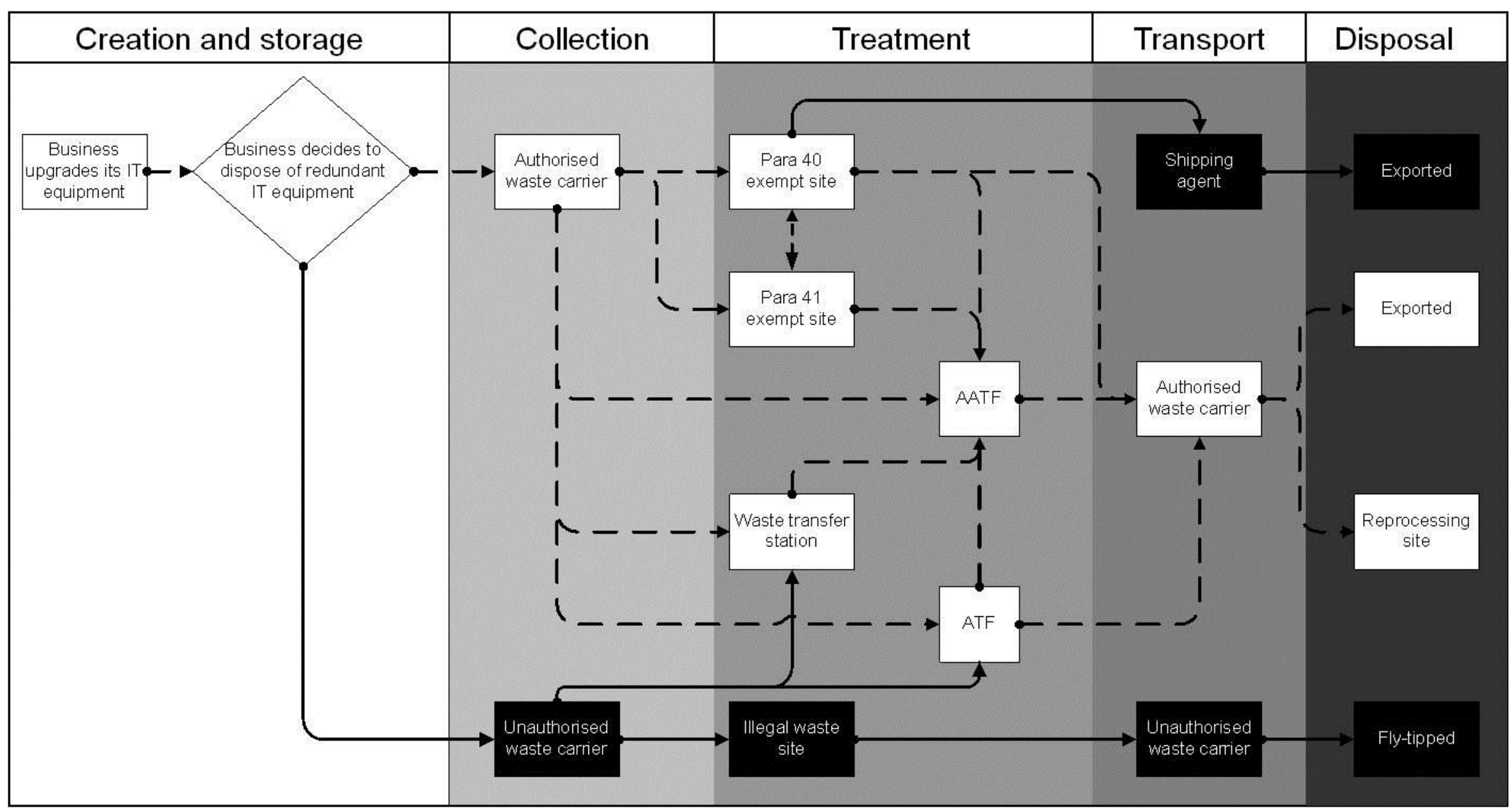

Figure 1. Waste flow chart for a WEEE example, illustrating both illegal and legitimate paths that the waste can follow. The solid black lines and black text boxes represent illegal waste activity involving unauthorised actors or unregulated sites (transactions that are not in accordance with the UK's environmental regulations). The dashed lines and white text boxes symbolise the desired, legitimate routes for the waste to take. 
public agencies responsible for regulating WEEE to raise awareness on these regulations to these types of operators, and on occasion raise attention to both the shipping lines and potential sources of WEEE of the illegal nature of any suspected shipments. This example also highlights the need for regulators to ensure that sites which pose a risk to illegal activity are appropriately monitored.

\section{Discussion}

Illegal waste activity is an international problem which is widely believed to be both evolving and growing (Czarnomski et. al., 2006; White, 2008; UNEP, 2010). The reason we say believed is because there are no known volumetric measures to assess the frequency or magnitude of this phenomenon. Emergent forms of criminality such as this often have the problem of data being in scarce supply, and as a result are difficult to study, and subsequently understand. This current situation prompted us to devise a methodology which could be used firstly to direct a data collection strategy, and secondly, as a template for conducting analysis on illegal waste activity.

To date, the study of illegal waste activity has been constrained by data collection and data quality issues (Gibbs and Simpson, 2009). Most crime analysis (conducted in policing agencies) is conducted using information that is recorded in databases on crime incidents. These include the type of crime, when it occurred, where it occurred, who the victim was, and a description of the suspect. Data on illegal waste activity are not recorded in a similar way, and this limits the application of tried and tested analytical techniques usually used in the study of crime. Yet, it is argued that there is a lot of information that can be gathered on illegal waste activity, but to do so requires a structured thought process on how to approach the analysis of illegal waste activity, the types of questions to ask, and the information to gather to help answer these questions. Script analysis fits well in such circumstances; as a technique it is more forgiving of information gaps than traditional statistical approaches, and is less dependent on precisely recorded data.

Initially, the script analysis approach helps to identify what information has been recorded on a particular illegal activity. This can span multiple agencies (both public and private sector) and be held in various databases, as well as coming from interviews with offenders (believed to be one of the most valuable sources of information). Drawing on this data, and aligning it to different 'acts' then exposes what key pieces of information have not yet been recorded. Those working through this thought process can set a clear investigative strategy through the information that is required. This information can then be added to the script as and when (and if) it becomes available. Once a script has been created, it can not only be used to support a specific investigation (on which the script is based), but can also be used to generate hypotheses on how an offender might exploit an opportunity to commit illegal waste activity. This may also involve postulating about the features that make this outcome more likely (i.e. those enabling conditions which encourage the illegal activity).

The script methodology is organic, and it can evolve and keep pace with the dynamic nature of the waste management industry. In this way, it can identify variations from an original script - or new tracks - making the methodology reflective and sensitive to offender innovation. Moreover, this approach provides a means of exploring and anticipating the likely impact of changes in legislation, technology and commercial practices on the opportunity structures for illegal waste activity and, hence, on the emergence of new crimes or methods of crime commission. Likewise, script analysis permits the testing of theoretical models, in that data and information can be structured to ascertain their consistency with a proposed model of expected behaviour. In the future, with greater sophistication, it is conceivable to think that scripts might form the basis of mathematically simulated models of behaviour, to further test theoretical scenarios.

In recognition of the very different profiles of EU Member States, and the structure of their regulatory systems, the script analysis methodology offered in this paper could be used as a standardisation tool for data collection across different countries. Likewise, we envisage that script analysis has the potential to synthesise analytical findings across international borders. For example, 
it could be used to build a repository of modi operandi knowledge from different nations, to help identify common features which link a set of illegal activity, and for detecting new trends. This type of knowledge transfer can also help identify approaches that can be used to investigate offences that display similar characteristics and the prosecution options that may be available. Furthermore, it could contribute to a better quantification of the extent of illegal waste activity across the international stage; something which to date has been elusive.

The script analysis methodology proposed in this paper is one possible first step towards gaining a better understanding of the nature of illegal waste activity. It is though a radical departure from how this phenomenon has been investigated and regulated to date. As such, it does require practitioners and researchers to begin to think more analytically about illegal waste activity, and structure their organisational processes accordingly.

It is anticipated that the initial adoption of this methodology will highlight many information gaps. In particular, the intricate details relating to illegal waste activity may not be available to populate all elements of a script. Due to data absences, some stages of the script may be better articulated, and hence understood, than others. This is a significant constraint, but in itself helps to provoke questions about what type of information are necessary to construct meaningful scripts, and the best way to extract this from investigative notes - something which is currently happening within the law enforcement agencies dealing with organised crime (Hancock and Laycock, 2010). Crystallising what qualitative data needs to be recorded to enable a quality script is an important developmental stage for the methodology. The discussions that ensue from this will serve to refine the methodology further and increase its value to practitioners.

Issues of sampling and representativeness are important limitations to acknowledge. Scripts will vary from offender to offender, and will only come to light when an offence is actually identified. It should be recognised that a select handful of case studies may not represent the wider picture of what is occurring, and that offenders who are identified may not be representative of the larger offending population. This affects the extent to which the analysis can be generalised, but the same is true for any analysis or research that relies on data extracted from known offending.

The interdependency between script analysis and the rational choice perspective may be seen by some to be inhibitive. Although the motivation of illegal waste activity is largely assumed to be economic - that is, it is perceived to be a rational, instrumental activity with clear material objectives - there may be other motivations that are, as yet, unknown. It is arguable whether every illegal waste crime that comes to light can be scripted according to rational motivations, at least by a (presumably) law-abiding researcher or practitioner who finds it hard to conceive how offenders might operate. For this reason, we encourage anyone wishing to use script analysis to consider whether the rational choice perspective embodies the theoretical stance taken to explain the behaviour being researched. To recapitulate a point made earlier, where there is a robust justification for doing so, other decision-making frameworks can be used in place of the rational choice perspective.

The principal advantage to using script analysis is that it elicits a specific, focused account of what illegal activity has occurred, and nests it within the wider context of the waste management system. This level of detail can be a great aid when considering how to present a prosecution case to the court. It is also fundamental when establishing what evidence needs to be collected to maximise the prosecution outcome (i.e. by determining the seriousness or frequency of illegal activity, greater sanctions may be imposed on the offender).

The level of detail achieved through script analysis can also help in devising preventative strategies. By tracing scenarios downstream - or upstream - from the known illegal activity, it is easier to see what chain of events has caused this activity to happen. By identifying the logical steps needed to be taken by an offender in their commission of a criminal event, it reveals a greater understanding of the possible intervention points (Ekblom, 1991; Johnson, Natarajan and Sanabria, 1993). 
Furthermore, this approach can facilitate more efficient monitoring of compliance to environmental regulations at specific points in the script, and thus can play a dual role in preventative strategies.

Transferring knowledge and techniques from academic research into the 'real world' is a noble goal, but one which happens all too seldom. Academics and practitioners need to work in tandem to achieve 'best practice' of the monitoring and enforcement of environmental regulations (White, 2008). Practitioners have much to gain from using research findings to direct their efforts, but often find that they are inaccessible, or not wholly relevant to what they wish to achieve. The analytical approach proposed in this paper takes an academic concept and, drawing from experience of attempting to analyse illegal waste activity, adapts it so that it might appeal to practitioners and researchers alike. The organic nature of the script analysis process offers an opportunity to more clearly identify illegal waste issues, and respond quickly to change and innovation in an area where illegal entrepreneurial expertise, opportunism, and responsiveness to changing market conditions set the pace.

\section{Conclusion}

In this paper we have explained and illustrated the use of script analysis as a way of better understanding illegal waste activity. Script analysis is an approach that has been used to help understand the processes that an offender adopts in the commission of a wide variety of crime, such as auto-vehicle theft, sexual offences and financial fraud. Our research has sought to translate script analysis into a method that elicits a greater understanding of the dynamics of illegal waste activity. This has included illustrating the use of crime scripts for two important functions; to help determine a data collection strategy, and as a tool to analyse illegal waste activity. In doing so, we argue that this approach elicits a specific, focused account of what illegal activity has occurred, and nests it within the wider context of the waste management system. We anticipate that using this methodology will provide academics and practitioners a means of enhancing the investigation, detection and prevention of illegal waste activity. 


\section{References}

Axion Recycling. (2006). WEEE Flows in London: An analysis of waste electrical and electronic equipment within the M25 from domestic and business sectors. Resource Document. http://londonremadenew.solutions2test.co.uk/Uploads/medialibrary/weeeflowsinlondon.pdf

Accessed 28 October 2010

Baken, J. (2004). The Corporation: The Pathological Pursuit of Profit and Power. London: Constable.

Beauregard, E., Proulx, J., Rossmo, K., LeClerc, B. \& Allaire, J. F. (2007). Script Analysis of the Hunting Process of Serial Sex Offenders. Criminal Justice and Behavior. 34(8), 1069-1084.

Block, A. (2002). Environmental Crime and Pollution: Wasteful Reflections. Social Justice, 29(1-2), 61 81.

Boba, R. (2005). Crime Analysis and Crime Mapping. Thousand Oaks, CA: Sage Publications Inc.

Brantingham, P. J. \& Brantingham, P. L. (1981) (Eds.). Environmental Criminology. Thousand Oaks, CA: Sage Publications Inc.

Brantingham, P. L. \& Brantingham, P. J. (1984). Patterns in Crime. New York: Macmillan.

Bruinsma, G. (1996) De afvalverwerkingsbranche, in G. Bruinsma and F. Bovenkerk, F., (eds.). Inzake opsporing: enquêtecommissie opsporingsmethoden, Deel II onderzoeksgroep Fijnaut: branches (The Hague 1996) 261-310.

Cornish, D. (1994). The Procedural Analysis of Offending and its Relevance for Situational Prevention. Resource Document. http://www.popcenter.org/library/crimeprevention/volume 03/06 cornish.pdf Accessed 28 October 2010.

Cornish, D. and Clarke, R.V. (1986). The Reasoning Criminal: Rational Choice Perspectives on Offending. New York: Springer-Verlag.

Cornish, D. B. and Clarke, R. V. (2008). 'The rational choice perspective'. In R., Wortley \& L., Mazerolle Environmental Criminology and Crime Analysis. Cullompton, UK: Willan Publishing.

Czarnomski, S., Webb, B. \& Holmes, A. (2006). IMPEL - TFS Threat Assessment Project: the illegal shipment of waste among IMPEL member states. Library document. http://impel.eu/wpcontent/uploads/2010/02/2006-x-Threat-Assessment-Final-Report.pdf Accessed 28 October 2010.

Darby, L. \& Obara, L. (2005). Household recycling behaviour and attitudes towards the disposal of small electrical and electronic equipment. Resources, Conservation and Recycling. 44, 17-35.

Dorn, N., Van Daele, S. \& Vander Beken, T. (2007). Reducing vulnerabilities to crime of the European waste management industry: the research base and the prospects for policy. European Journal of Crime, Criminal Law and Criminal Justice, 15(1), 23-36.

Ekblom, P. \& Sidebottom, A. (2008). What Do You Mean, 'Is It Secure?' Redesigning Language to be Fit for the Task of Assessing the Security of Domestic and Personal Electronic Goods. European Journal of Criminal Policy and Research. 14, 61-87.

Ekblom, P. \& Tilley, N. (2000). Going Equipped. The British Journal of Criminology. 40 (3): 376-398

Ekblom, P. (1991). Talking to Offenders: Practical Lessons from Local Crime Prevention. In: O. Nello (ed.). Urban Crime: Statistical Approaches and Analyses. International seminar held under the auspices of Ajuntament de Barcelona Forum des Collectives Territoriales Europeenes pour la Securit6 Urbaine. Barcelona: Institut d'Estudis Metropolitans de Barcelona. 
Elliot, L. (2009). Combating transnational environmental crime: "Joined up" thinking about transnational networks. In K. Kangaspunta \& .I Marshall (eds.). Eco-Crime and Justice: Essays on Environmental Crime. Turin, Italy : Public Information Department of UNICRI.

Gibbs, C. \& Simpson, S. S. (2009). Measuring corporate environmental crime rates: progress and problems. Crime Law Soc Change, 51, 87-107.

Gibbs, C., Gore, M. L., McGarrell, E. F. \& Rivers, L. (2010). Introducing Conservation Criminology: Towards Interdisciplinary Scholarship on Environmental Crimes and Risks. The British Journal of Criminology. 50(1), 124-144.

Gibbs, C., McGarrell, E. F., \& Axelrod, M. (2010). Transnational white-collar crime and risk: Lessons from the global trade in electronic waste. Criminology \& Public Policy, 9(3), 543-560.

Hancock, G. \& Laycock, G. (2010). "Organised crime and crime scripts: prospects for disruption”. In K. Bullock, R. V. Clarke \& N. Tilley (Eds.) Situational Prevention of Organised Crimes. Cullompton, UK: Willan Publishing.

Herbig, F. J. W. \& Joubert, S. J. (2006). Criminological Semantics: Conservation Criminology - Vision or Vagary? Acta Criminologica. 19(3), 88-103.

Home Office (2010). Information sharing for community safety: guidance and practice advice. London: Home Office.

Johnson, B. D., Natarajan, M. \& Sanabria, H. (1993). Successful Criminal Careers: Toward an Ethnography Within the Rational Choice Perspective. In R. V. Clarke and M. Felson (Eds.). Routine Activity and Rational Choice. Advances in Criminological Theory. Vol. 5. New Brunswick, NJ: Transaction Press.

Kennedy, D. (2008). Deterrence and Crime Prevention: Reconsidering the Prospect of Sanction. Routledge.

Lacoste, J. \& Tremblay, P. (2003). Crime innovation: A script analysis of patterns in check forgery. In M. J. Smith \& Cornish, D. B. (Eds.) Crime Prevention Studies. Vol 16, 171-198.

Lynch, M. (1990). The Greening of Criminology: A Perspective of the 1990s. The Critical Criminologist. 2(3), 1-4 and 11-12

Massari, M. \& Monzini, P. (2004). Dirty businesses in Italy: a case-study of illegal trafficking in hazardous waste. Global crime. 6(3-4), 285-304.

Morselli, C. \& Roy, J. (2008). Brokerage Qualifications in Ringing Operations. Criminology. 46(1), $71-$ 98.

Nisbett, R.E. \& Ross, L. (1980). Human Inference: Strategies and Shortcomings of Social Judgement. Englewood Cliffs, NJ: Prentice-Hall.

Ratcliffe, J. H. (2008). Intelligence-Led Policing. Cullompton: Willan Publishing

Schmidt, C. (2004). Environmental Crimes: Profiting at the Earth's Expense. Environmental Health Perspectives, 112(2): A96-A103.

Simon, D. (2000). Corporate Environmental Crimes and Social Inequality: New Directions for Environmental Justice Research. American Behavioural Scientist, 43(4), 633-645.

Tremblay, B., Talon, B. \& Hurley, D. (2001). Body Switching and Related Adaptations in the Resale of Stolen Vehicles. Script Elaborations and Aggregate Crime Learning Curves. The British Journal of Criminology. 41(4), 561-579. 
UNEP (2010). Recycling - from E-Waste to Resources. Resource Document. http://www.unep.org/PDF/PressReleases/E-Waste publication screen FINALVERSION-sml.pdf Accessed 28 October 2010.

White, R. (2008). Crimes Against Nature: Environmental Criminology and Ecological Justice. Cullompton: Willan Publishing.

Willison, R. \& Siponen, M. (2009). Overcoming the insider: reducing employee computer crime through Situational Crime Prevention. Communications of the ACM. 52(9), 133-137.

Wikström, P.-O. (2006), "Individuals, Settings, and Acts of Crime: Situational Mechanisms and the Explanation of Crime," in The Explanation of Crime : Context, Mechanisms, and Development (1 ed.), eds. P.-O. Wikström and R. J. Sampson, Cambridge: Cambridge University Press, pp. 61 - 107.

Wortley, R. \& Mazerolle, L. Environmental Criminology and Crime Analysis. Cullompton, UK: Willan Publishing. 